\title{
A Comparative Study on Seismic Analysis of Bangladesh National Building Code (BNBC) with Other Building Codes
}

\author{
Md. S. Bari • T. Das
}

Received: 8 September 2012/Accepted: 17 February 2014/Published online: 15 March 2014

(c) The Author(s) 2014. This article is published with open access at Springerlink.com

\begin{abstract}
Tectonic framework of Bangladesh and adjoining areas indicate that Bangladesh lies well within an active seismic zone. The after effect of earthquake is more severe in an underdeveloped and a densely populated country like ours than any other developed countries. Bangladesh National Building Code (BNBC) was first established in 1993 to provide guidelines for design and construction of new structure subject to earthquake ground motions in order to minimize the risk to life for all structures. A revision of BNBC 1993 is undergoing to make this up to date with other international building codes. This paper aims at the comparison of various provisions of seismic analysis as given in building codes of different countries. This comparison will give an idea regarding where our country stands when it comes to safety against earth quake. Primarily, various seismic parameters in BNBC 2010 (draft) have been studied and compared with that of BNBC 1993. Later, both 1993 and 2010 edition of BNBC codes have been compared graphically with building codes of other countries such as National Building Code of India 2005 (NBC-India 2005), American Society of Civil Engineering 7-05 (ASCE 7-05). The base shear/ weight ratios have been plotted against the height of the building. The investigation in this paper reveals that BNBC 1993 has the least base shear among all the codes. Factored Base shear values of BNBC 2010 are found to have increased significantly than that of BNBC 1993 for low rise buildings $(\leq 20 \mathrm{~m})$ around the country than its predecessor. Despite revision of the code, BNBC 2010 (draft) still suggests less base shear values when compared to the
\end{abstract}

Md. S. Bari $(\varangle) \cdot$ T. Das

Department of Civil Engineering, BUET, Dhaka 1000,

Bangladesh

e-mail: sbari@ce.buet.ac.bd
Indian and American code. Therefore, this increase in factor of safety against the earthquake imposed by the proposed BNBC 2010 code by suggesting higher values of base shear is appreciable.

Keywords BNBC $\cdot$ NBC $\cdot$ Seismic design provision · Comparative study

\section{Introduction}

Bangladesh lies well within an active seismic zone and is prone to earthquakes. To determine earthquake forces on a structure, static analysis has gained popularity in the country and also in many other countries because of the simplicity of the method. This calls for the use of an established and tested building code so as to ensure the safety of the structure and its occupants against the natural hazard. Bangladesh National Building Code (BNBC) was first organized in the year of 1993 to fulfill the purpose [1]. As the number of high rise buildings is increasing, the international codes followed for building design, detailing and construction is revised quite frequently to adopt the new practices. Initiative has already been taken to update BNBC 1993 and a draft copy has already been prepared [2] called BNBC 2010 (draft). A total change at wind load and earthquake provisions in the proposed code can be noticed $[1,2]$. This paper is aimed to review and compare the current and proposed seismic design provisions dealing with the specification of seismic design forces among the existing and recently proposed BNBC codes as well as other codes of different countries. The researcher have made a similar study [3] where they compared the BNBC 1993 code with contemporary codes like Uniform Building Code (UBC) 91 and UBC 97, National Building Code of 
India, 1983 (NBC India-83), and Outline Code of Bangladesh, 1979.

\section{Objective}

The main objective of this work is to compare the current seismic provision with the coming one as well as well known seismic provisions of other countries. In detail, the objectives are:

1. To become familiar with new seismic design methodology as described in BNBC 2010 (Draft).

2. To compare similarities as well as differences between BNBC 1993 and BNBC 2010 (Draft).

3. To compare BNBC code (both the existing and proposed editions) with National Building Code of India 2005 (NBC-India 2005) [4] and American Society of Civil Engineering (ASCE 7 05) [5].

\section{Methodology}

The method of calculation of seismic loading is more or less same in BNBC 2010 (draft) and BNBC 1993. Both these codes consider the earthquake force as a lateral force. The forces are determined on the basis of a base shear by Equivalent Lateral Force procedure. Base shear is calculated on the basis of seismic zone factor, structural importance factor and response reduction factor which is a function of structural system. Time period and soil type as a function of acceleration spectrum $\left(\mathrm{C}_{\mathrm{s}}\right)$ defined by BNBC 2010 and as a function of numerical coefficient (C) defined by BNBC 1993 are used in the expression of base shear (Table 1). The base shear/weight ratios have been compared graphically with respect to the height of the building. NBC-India 2005 code also follows somewhat similar approach [3]. Base shear/weight ratios are computed from the given formula and hence plotted against height.
Like all modern codes, zone factor is replaced in ASCE 705 code by two numbers $S_{s}$ and $S_{1}$ for the specific geographic location (latitude and longitude) of the project site representing response spectrum acceleration at shorter and $1 \mathrm{~s}$ period respectively as a percentage of gravity [4]. Electronic values of mapped acceleration parameters all around the world are found at the USGS Web site at http://earthquake.usgs.gov/designmaps and are directly used in the base shear expression to plot a comparative graph with the BNBC codes [6].

\section{Comparison of Various Parameters}

\section{Seismic Zone Factor (Z)}

On the basis of distribution of earthquake epicenters, ground motion attenuation, geophysical and tectonic data available from within as well as outside of the country [7], Bangladesh was mapped dividing into three generalized seismic zones in BNBC 1993. The seismic zoning map is revised in the proposed BNBC 2010 with provisions for four seismic zones with different level of ground motion. Each zone has a seismic zone coefficient $(Z)$ which represents the maximum considered peak ground acceleration (PGA) on very stiff soil/rock (site class SA) in units of $g$ (acceleration due to gravity) The northeastern folded regions of Bangladesh are the most active zones and has a maximum PGA value of $0.36 \mathrm{~g}$. Therefore, northern east areas of the country are given highest priority in the both existing and proposed edition of BNBC. Seismic zone factor is increased considerably in BNBC 2010.

\section{Structural Importance Factor (I)}

In BNBC 1993, structure importance co-efficient is different for structural and non-structural components and equipment and denoted by I. But in BNBC 2010 (draft), importance co-efficient is denoted by I for all cases. In

Table 1 Seismic parameters of the codes in a nutshell

\begin{tabular}{|c|c|c|c|}
\hline BNBC 1993 & BNBC 2010 & NBC-India 2005 & ASCE 710 \\
\hline $\begin{array}{l}V=\frac{\mathrm{ZIC}}{R} W, \mathrm{~V}=\text { Base shear, } \\
\mathrm{Z}=\text { Seismic zone factor, } \\
\mathrm{I}=\text { Structure importance factor, } \\
\mathrm{W}=\text { Total dead load }+ \text { some } \\
\text { specified live loads, } \\
\mathrm{R}=\text { Response modification } \\
\text { coefficient, } \mathrm{C}=\text { Numerical } \\
\text { coefficient } \\
C=\frac{1.25 S}{T^{2 / 3}}, \mathrm{~S}=\text { Site coefficient for } \\
\text { soil characteristics, } \mathrm{T}=\text { Time } \\
\text { period }\end{array}$ & $\begin{array}{l}V=\frac{2}{3} \frac{Z I C_{s}}{R} W, \mathrm{~V}=\text { Base shear, } \\
\mathrm{Z}=\text { Seismic zone factor, } \\
\mathrm{I}=\text { Structure importance factor, } \\
\mathrm{W}=\text { Total dead load }+ \text { some } \\
\text { specified live loads, } \\
\mathrm{R}=\text { Response reduction factor, } \\
\mathrm{C}_{\mathrm{s}}=\text { Normalized acceleration, } \\
\text { Response spectrum }=\mathrm{f} \text { (time } \\
\text { period } \mathrm{T}, \text { soil factor } \mathrm{S} \text { and } \\
\text { damping factor) }\end{array}$ & $\begin{array}{l}V_{B}=\frac{Z I}{2 R} \times \frac{S_{a}}{g} W, \mathrm{~V}_{\mathrm{B}}=\text { Base shear, } \\
\mathrm{Z}=\text { Seismic zone factor, } \\
\mathrm{I}=\text { Importance factor, } \\
\mathrm{W}=\text { Seismic weight, } \\
\mathrm{R}=\text { Response reduction factor, } \\
\mathrm{S}_{\mathrm{a}} / \mathrm{g}=\text { Average response, } \\
\text { acceleration coefficient }\end{array}$ & $\begin{array}{c}V=\frac{S_{D S}}{R / I_{e}} W \leq \frac{S_{D 1}}{T\left(R / I_{e}\right)} W, \mathrm{~V}=\text { Base } \\
\text { shear, } \mathrm{I}_{\mathrm{e}}=\text { Importance factor, } \\
\mathrm{W}=\text { Effective seismic weight, } \\
\mathrm{R}=\text { Response modification } \\
\text { factor, } \mathrm{S}_{\mathrm{DS}}=\text { Design spectral } \\
\text { response acceleration parameter } \\
\text { at shorter period, } \mathrm{SD} 1=\text { Design } \\
\text { spectral response acceleration } \\
\text { parameter at } 1 \mathrm{~s}, \\
\mathrm{~T}=\text { Fundamental time period }\end{array}$ \\
\hline
\end{tabular}


BNBC 1993, importance co-efficient is described for four different cases whereas it is described for five different cases in BNBC 2010. The descriptions of the cases in old and new codes are completely different. Importance coefficient is found higher in BNBC 2010 and increased up to $25 \%$ for some cases.

\section{Soil Factor (S)}

This is termed as site coefficient in BNBC 1993. The amount of ground motion amplification depends on wavepropagation characteristics of soils, which can be estimated from the measurements of shear wave velocity. Soft soils with slower shear wave velocities generally produce greater amplification than stiff soils with faster shear wave velocities. The site classes are defined mainly in terms of soil profile depth and shear wave velocity in the existing code. BNBC 2010 includes additional two procedures to determine the site classes as measuring shear wave velocity adds cost to a geotechnical investigation. Such classification is based on Standard Penetration Resistance, Untrained Shear Strength [8].

\section{Response Reduction Factor $(R)$}

In BNBC 1993, it is known as response modification coefficient. It is the factor by which the actual base shear force that would develop if the structure behaved truly elastic during earth quake is reduced to obtain design base shear. This reduction is allowed to account for the beneficial effects of inelastic deformation that can occur in a structure during a major earthquake. The value of response modification factor is significantly reduced in BNBC 2010 for different structural systems (Table 2). This reduction is logical since only two-third of the maximum considered earthquake (MCE) ground motion is considered to be design basis earth quake in BNBC 2010 rather than full MCE in BNBC 1993.

\section{Time Period (T)}

The fundamental building period is simply the inverse of the building frequency at which it wants to vibrate when set in motion by some sort of disturbance (in building design, typically a seismic or wind event) based on the system's mass and stiffness characteristics. Buildings with shorter fundamental periods attract higher seismic forces as the code-based design spectrum exhibits higher accelerations at shorter periods.

The building period $\mathrm{T}$ in seconds may be approximated in both the codes by the following formula:

$T=C_{t} h_{n}^{m}, \mathrm{~h}_{\mathrm{n}}$ is the height of the building in meter.

The value of $C_{t}$ and $m$ are different in the two codes (Table 3).

\section{Normalized Response Spectrum Acceleration $\left(C_{s}\right)$}

Code-based response spectrum is similar to Numerical coefficient of BNBC 1993 in a sense that both are functions of time period (T) and site characteristics (S). But2010 edition of the code introduces an additional parameter Damping Factor as a function of response spectrum. Damping factor is the effect of inherent energy dissipation mechanisms in a structure (due to sliding, friction, etc.) that results in reduction of effect of vibration, expressed as a percentage of the critical damping for the structure. BNBC 2010 suggests that $5 \%$ damped design spectrum to be properly modified for an actual damping factor. BNBC 2010 introduces four equations each operating within a range of time period to determine $\mathrm{C}_{\mathrm{s}}$.

\section{Seismic Weight $(W)$}

Seismic weight is the total dead load of building or structure, including partition walls, and applicable portions of other imposed loads. In BNBC 2010 (draft) a minimum of $25 \%$ of live load is applicable for live load less than equal

Table 2 Comparison of response reduction factor between BNBC 1993 and 2010

\begin{tabular}{lllll}
\hline Structural system & Description of lateral force resisting system & BNBC 1993 & BNBC 2010 & Percent decreased \\
\hline Building frame system & Steel eccentrically braced frame & 10 & 8 & 20 \\
& Reinforced concrete shear wall & 8 & 5 & 37.5 \\
& Special reinforced concrete shear wall & - & 6 & - \\
& Ordinary steel concentrically braced frame & - & 3.25 & - \\
& Special concentrically braced frame & 8 & 6 & 25 \\
Moment resisting frame system & Special steel moment resisting frame & 12 & 8 & 33.33 \\
& Special concrete moment resisting frame & 12 & 33.33 \\
& Intermediate concrete moment resisting frame & 8 & 37.5 \\
& Ordinary steel moment resisting frame & 6 & 3.5 & 41.67 \\
& Ordinary concrete moment resisting frame & 5 & 3 & 40 \\
\hline
\end{tabular}


Table 3 Comparison of time period parameters

\begin{tabular}{|c|c|c|c|c|}
\hline \multirow[t]{2}{*}{ Structure type } & \multicolumn{2}{|c|}{ BNBC 2010} & \multicolumn{2}{|c|}{ BNBC 1993} \\
\hline & $\mathrm{C}_{\mathrm{t}}$ & $\mathrm{m}$ & $\mathrm{C}_{\mathrm{t}}$ & $\mathrm{m}$ \\
\hline Concrete moment resisting frame & 0.0466 & 0.9 & 0.073 & 0.75 \\
\hline Steel moment resisting frame & 0.0724 & 0.8 & 0.083 & 0.75 \\
\hline Eccentric based steel frame & 0.0731 & 0.75 & 0.073 & 0.75 \\
\hline All other structural systems & 0.0488 & 0.75 & 0.049 & 0.75 \\
\hline
\end{tabular}

$3 \mathrm{KN} / \mathrm{m}^{2}$, otherwise $50 \%$. But in BNBC 1993 a minimum of $25 \%$ of the floor live load shall be applicable irrespective of live load. Total weights of permanent equipments are considered in both codes. Allowance for partition wall is considered in BNBC 93 but it is not considered in BNBC 2010 (Draft). In Indian code seismic weight is the total dead load plus appropriate amounts of specified imposed load.

\section{Base Shear and Its Distribution}

A comparison of base shear is the simplest way to compare the final result. But to make it more generalized, the base shear/weight ratios are plotted against the height of the building. Only RC ductile moment resisting framed buildings have been dealt with, because of the wide use of this structure in Bangladesh. The zones with similar seismic activity are considered and loose soil condition has been assumed. For simplicity, building with no horizontal and vertical irregularities has been considered. Sylhet being the region of the highest seismicity in Bangladesh is considered as the location for the mapped zone factor in Fig. 1.

In Ultimate Strength Design method, the nominal earthquake loads are multiplied by a factor called Load Factor. They remain in combination with other loads and termed as Factored Load. The earthquake load combinations of the codes compared here are shown in the Table 4. After incorporating the corresponding maximum load factors of the BNBC 1993 and BNBC 2010, the previous graph is reconstructed and found like Fig. 2.

There has been found increased factored base shear in BNBC 2010 at low rise buildings $(\leq 20 \mathrm{~m})$ around various districts. Also, it can be realised that at higher altitude, the difference between the two codes becomes very small. The above plots will alter amplitude for the different locations, site classes and structural systems of the building in question but the nature of the curve remains the same. Therefore, BNBC 2010 surely imposes higher base shear than BNBC 1993 for buildings irrespective of site classes and structural systems (Figs. 1 and 2).

The vertical distribution of seismic forces of the BNBC 2010 is different from that of BNBC 1993. The BNBC

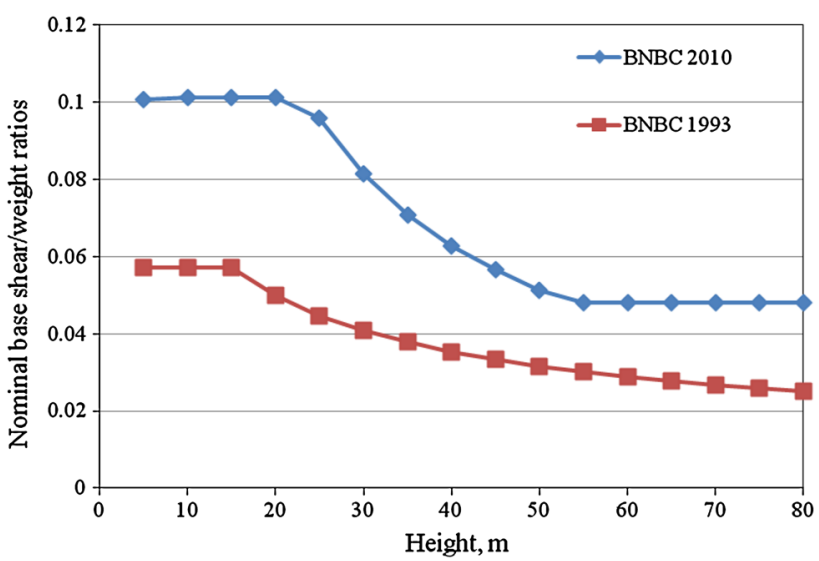

Fig. 1 Comparison of seismic nominal base shear of RC SMRF type building for loose soil condition in Sylhet

2010 prescribes a linear distribution and a parabolic distribution for structures with $T<0.5 \mathrm{~s}$ and $T>2.5 \mathrm{~s}$ respectively varying from a zero value at the base to a maximum value at the top. For intermediate periods, one may use a linear interpolation between a linear and a parabolic distribution, or a parabolic distribution which is more conservative. The BNBC 1993 code uses a linear distribution, with zero value at the base, for structures with $T<0.7 \mathrm{~s}$. For longer-period structures, a portion of the design base shear $(0.07 T V \leq 0.25 \mathrm{~V})$ is concentrated at the top, with the remainder of the design base shear being distributed linearly as for short-period structures.

\section{Comparision of BNBC with Other Building Codes}

\section{With NBC-INDIA 2005}

Northern part of Bangladesh is surrounded by the regions of high seismicity which includes the Shillong plateau having possessed by multiple faults. Since these parts of Bangladesh and India can be characterized by the same tectonic features, computation of base shear for those zones following respective codes will highlight the design standards of these two countries against earthquake. Both BNBC (1993 and 2010) and NBC-India 2005 put the 
Table 4 Comparison of load factors

\begin{tabular}{llll}
\hline Load combinations in USD method & & & \\
\hline BNBC 1993 & BNBC 2010 & NBC-India 2005 & ASCE 705 \\
\hline $1.05 \mathrm{D}+1.275 \mathrm{~L}+1.4 \mathrm{E}$ & $1.2 \mathrm{D}+1.0 \mathrm{E}+1.0 \mathrm{~L}$ & $1.2 \mathrm{D}+1.2 \mathrm{~L}+1.2 \mathrm{E}$ & $1.2 \mathrm{D}+1.0 \mathrm{E}+1.0 \mathrm{~L}$ \\
$0.9 \mathrm{D}+1.43 \mathrm{E}$ & $0.9 \mathrm{D}+1.0 \mathrm{E}$ & $0.9 \mathrm{D}+1.5 \mathrm{E}$ & $0.9 \mathrm{D}+1.0 \mathrm{E}$ \\
\hline
\end{tabular}

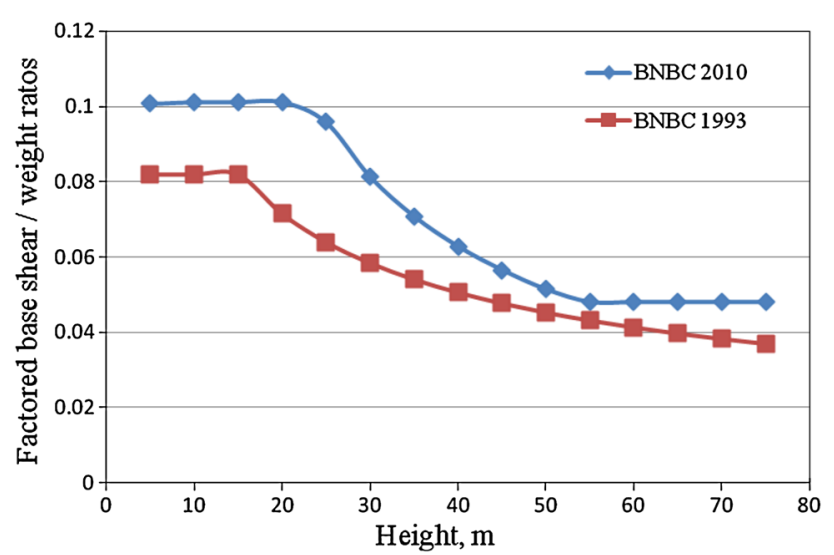

Fig. 2 Comparison of seismic factored base shear of RC SMRF type building for loose soil condition in Sylhet

highest priority in these most severe earthquake prone zones by suggesting the highest seismic zone factor, $Z=0.36$. Consideration of Soil with identical geotechnical features is important in comparing the base shear values as different types of soil subject to different sorts of ground motion. Soil type S3, SD and soft soil condition as per BNBC 1993, BNBC 2010 and NBC-India 2005 respectively is assumed for their identical geotechnical characteristics $(N<15$, where $N=$ standard penetration value). The maximum load factors of $1.43,1$ and 1.5 against earthquake for BNBC 1993, BNBC 2010 and NBC-India 2005 are taken into account to plot the graphs.

Figure 3 is a plot of factored base shear for the maximum seismic loading that is governed by each of the respective codes and it shows proposed BNBC code exceeds the Indian code by some margins. Another graph (Fig. 4) is plotted below showing the seismic base shear for Jessore and Kolkata having similar tectonic and geological features but defined as low and moderate seismic intensity zone respectively in the respective codes. Due to the absence of Intermediate Moment Resisting Frame (IMRF) in the building system of the Indian code, Special Moment Resisting Frame (SMRF) as a lateral load resisting system is considered for moderate seismic risk. Soil type is assumed as before. Kolkata is found higher in terms of factored base shear.

Fundamental difference in the Indian and Bangladesh standard may be attributed to the fact that the design earth

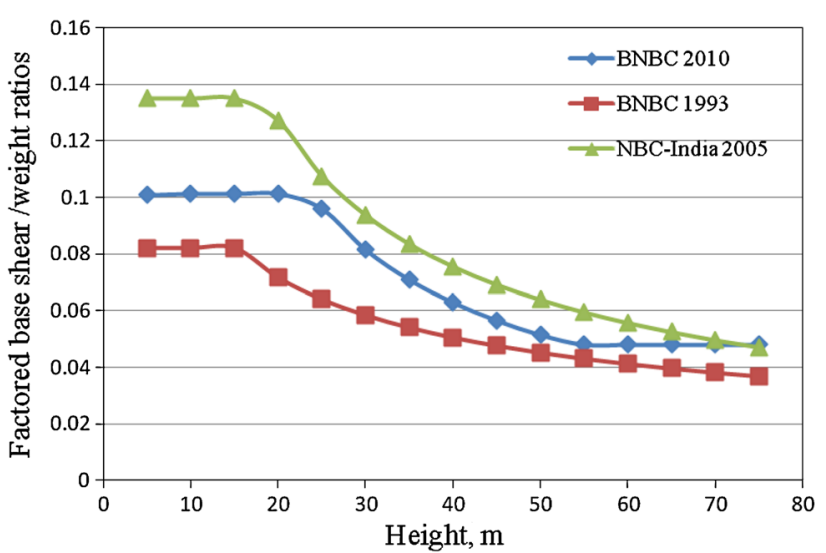

Fig. 3 Comparison of factored base shear between BNBC and NBCIndia 2005 codes for Sylhet and Shillong regions at loose soil condition

quake of BNBC 2010 is two-third of Maximum Considered Earthquake (MCE) while the Indian standard designs with one half of MCE. This indicates buildings in Bangladesh will collapse form an earthquake that is 1.5 times larger than design earthquake while buildings in India will collapse from 2 times larger earthquake than corresponding design earthquake.

\section{With ASCE 705}

The ASCE 705 code is the basis of most state seismic codes. The seismic criteria of International Building Code (IBC) are taken from ASCE 705 . ASCE 705 code provides seismic ground motion parameters as spectral acceleration coefficients $S_{s}$ and $S_{1}$ (spectral response accelerations at 0.2 and $1.0 \mathrm{~s}$, respectively, for $5 \%$ of critical damping) assuming Site Class "B" with $2 \%$ probability of exceedance in 50 years. For the ASCE 705 , these acceleration values come from the 2002 United States Geological Survey (USGS) seismic hazard maps, which are available from www.usgs.gov [9].

Worldwide seismic design maps web application provides earthquake shaking parameters, more specifically, $\mathrm{S}_{\mathrm{s}}$ and $S_{1}$ values worldwide that are needed for seismic design of structures using the ASCE 705 code and similar standards (e.g., the IBC/SEI standard). This application mainly uses gridded data from the Global Seismic Hazard 


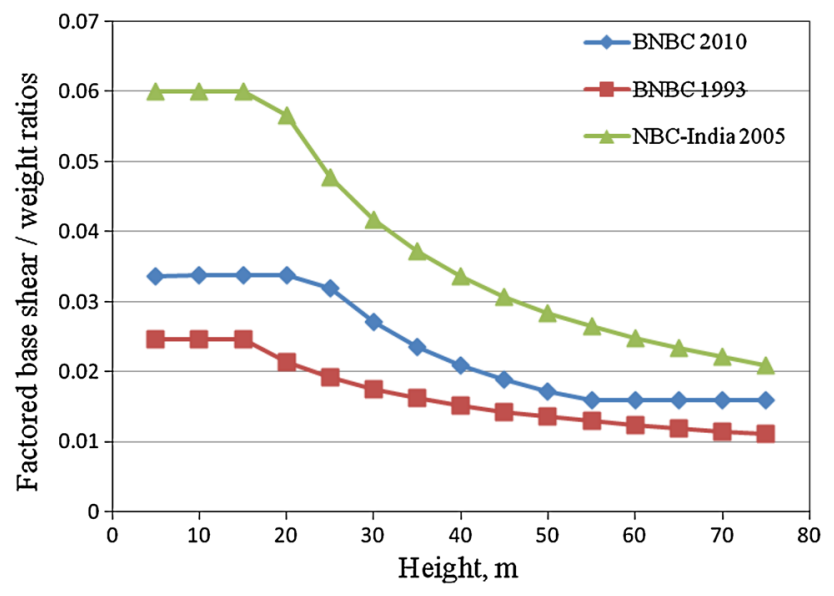

Fig. 4 Comparison of factored base shear between BNBC and NBCIndia 2005 codes for Jessore and Kolkata cities at loose soil condition

Assessment Program (GSHAP) project for South Asia region. The GSHAP data cover much of the world with the major exceptions being vast expanses of ocean. $S_{s}$ and $S_{1}$ values are approximate values based on the probabilistic $10 \%$-in-50-year PGA's from GSHAP. The GSHAP values are multiplied by 2 to approximate $2 \%$-in-50-year PGA values, and then multiplied by 2.5 and 1.0 , respectively, to estimate $\mathrm{S}_{\mathrm{s}}$ and $\mathrm{S}_{1}$. This application is used here as a tool to gather a preliminary assessment of the seismic design parameters for Bangladesh to make a comparison with the ASCE 705 standard.

According to the ASCE 7 05, each building is assigned to one of the six structural design categories (SDC) depending on risk category and the values of $S_{s}$ and $S_{1}$. On such basis, Sylhet is found to be under SDC D. The base shear/weight ratios are plotted for Sylhet following Equivalent Lateral Procedure which is applicable to a SDC $\mathrm{D}$ category building with no certain vertical or horizontal irregularities unless $\mathrm{T}>3.5 \mathrm{~T}_{\mathrm{s}}$. Since BNBC 2010 and ASCE 705 have similar load factors, graph is plotted on the basis of nominal base shear. Existing BNBC 1993 code provides less base shear values compared to ASCE 705 standard. But the revised base shears in the proposed BNBC 2010 code will definitely be much closer to that of ASCE 705 standard (Fig. 5).

\section{Conclusion}

BNBC 1993 suggests the least base shear values among the current codes compared in this paper. While developed countries are going for more conservative design, this contradiction of BNBC-93 could be suicidal. Some modifications are needed to be made in this respect. Proposed BNBC 2010 will surely be a more conservative approach in the seismic design of buildings in Bangladesh. Base shear

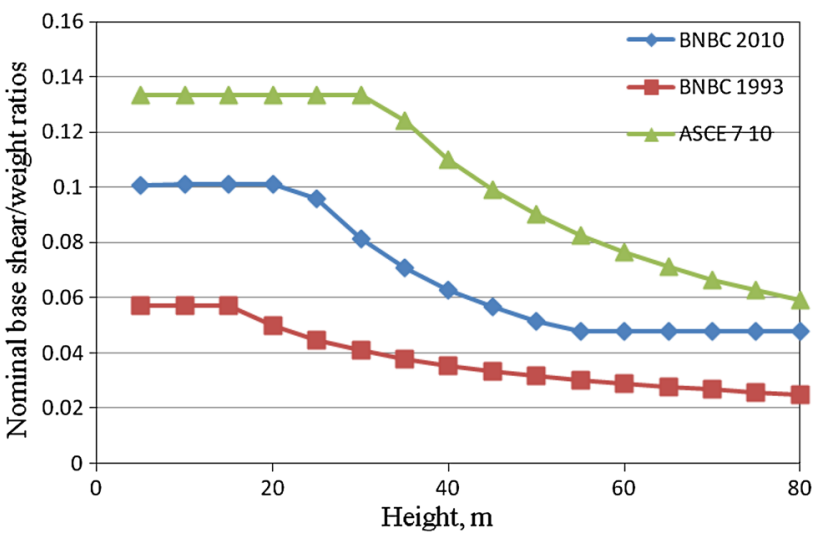

Fig. 5 Comparison of nominal base shear between BNBC codes (both 1993 and 2010) and ASCE 705 code for loose soil condition in Sylhet

values of BNBC 2010 are found to have increased significantly than that of BNBC 1993 for low rise buildings $(\leq 20 \mathrm{~m})$ around the country.

But BNBC 2010 has less base shear value as compared to ASCE 705 for low storied buildings $(\leq 20 \mathrm{~m})$. Because the ASCE 705 code design parameters are generic, they also generally impose higher base shear values. As India is the closest neighbor to Bangladesh and shares the same tectonic zone, comparison with the Indian standard will be of more significance. Looking at the Indian standard, the design seismic loading set by BNBC 2010 seems to be well justified as the nominal base shears in the proposed standard are relatively closer to that of NBC-India 2005.

Therefore, this increase in factor of safety against the earthquake imposed by the proposed BNBC 2010 code by suggesting higher values of base shear is appreciable. But remarkably higher reinforcement requirement in ground floor column of low storied buildings than before might be a concern for building design in Bangladesh by the proposed code. Further studies need to be made in this aspect.

Open Access This article is distributed under the terms of the Creative Commons Attribution License which permits any use, distribution, and reproduction in any medium, provided the original author(s) and the source are credited.

\section{References}

1. Bangladesh National Building Code, BNBC, Earth Quake Loads Part 6 Chap. 2 Section 2.5 (Housing and Building Research Institute and Bangladesh Standard and Testing Institute, Bangladesh, 1993)

2. Bangladesh National Building Code, BNBC (Draft) Earth Quake Loads Part 6 Chap. 2 Section 2.5 (2010)

3. F. Atique, Z. Wadud, A comparison of BNBC-93 with other building codes with respect to earthquake and wind analysis, in The Eighth East Asia-Pacific Conference on Structural Engineering and Construction, (Nanyang Technological University, Singapore, 2001) 
4. National Building Code-India, Load, Forces and Effects, Part 6, Section 1. (Bureau of Indian Standards, New Delhi, 2005)

5. American Society of Civil Engineering 705 code, ASCE 705 (2005), Chapter 11 Seismic design criteria and Chapter 12 seismic design requirement of building structures. American Society of Civil Engineers, Drive Reston

6. Information at http://earthquake.usgs.gov/designmaps last updated on 11 Feb 2013. Accessed 12 Aug 2012
7. M.H. Ali, Earthquake database and seismic zoning of Bangladesh (1998)

8. D. Kelly, Seismic site classification for structural engineers (2006), http://www.structuremag.org/Archives/2006-12/SF-SEISMIC-Dec06p21-24.pdf. Accessed 10 Aug 2012

9. Information at http://www.usgs.gov last updated on 7 Jan 2014. Accessed 12 Aug 2012 